\section{THE TREATMENT OF PERFORATED GASTRIC AND DUODENAL ULCERS.}

With a Report on Forty Consecutive Cases.*

\author{
BY
}

\section{G. PERCIVAJ, MIILS, F.R.C.S.,}

\author{
assistant SURGeon to the general hospital, birMinghax.
}

THis paper is a plea for the performance of gastrojejunostomy whenever possible at the time of operation for perforation. Beginning with some apprehension, I have been led to do so more and more frequently with increasing experience, and $I$ now regard it as almost a routine part of the operation.

The cases analysed below are all those I have treated in hospital since my return from the war: 16 were duodenal, 15 pre-pyloric, 5 in the body of the stomach, and in 4 the situation of the ulcer is not stated in the notes. There were 38 males and 2 females.

\section{Treatment.}

Every case but one was operated on. This patient was moribund on admission, and failed to rally with treatment. The death is included in the mortality statistics. In early cases, seen within about twelve hours of perforation, suture of the ulcer and gastro-jejunostomy was performed without drainage of the peritoneum, except in three instances of very severe soiling, in which a suprapubic drain was put to the bottom of the pelvis. I have long discontinued drainage through the main wound. The same treatment was adopted in a few late cases in which the patient, in spite of long perforation, was still in good condition. In the majority of late cases suture of the ulcer and pelvic drainage was all that was attempted. A single row of sutures covered by omentum was used, and this proved mechanically efficient to prevent further leakage. I believe it is waste of valuable time to put several rows of sutures.

\section{Mortality.}

Of the whole series 11 died, including the case not operated on--a gross mortality of 27.5 per cent.

Of 22 cases in which immediato gastro-jejumostony was done, one died-a mortality of 4.5 per cent. The death was due to pneumococcal peritonitis seven days after operation.

Of 17 cases in which suture and drainage without gastrojejunostomy were done, 9 died-a mortality of 52.9 per cent. This high mortality, of course, reflects the fact that the operation was reserved for the worst cases. Five of them died within twenty-four hours of operation of peritoneal shock, three a few days later from peritonitis, and one from acute nephritis and uraemia.

A striking fact about the series is the complete absenco of what $I$ used to regard as a common complicationsubphrenic abscess. I attribute this to the fact that I put no drainage tubes into the upper abdomen. It might be supposed that subphrenic abscess would be commoner in these circumstances, but clearly the reverse is the case, for since I gave up draining the upper abdomen I have lad no subphrenic abscess.

\section{End-results.}

All the patients operated on over six months ago were written to, and several were seen personally. Of the 29 survivors 22 were traced.

Cases without Gastro-jejunostomy-Traced 8, perfectly well 1, still serious gastric trouble 5 , relieved by subsequent gastrojejunostomy 1 , died of carcinoma 1 . Thus of eight cases only one was cured

Cases with Gastro-jejunostomy.-Traced 14, perfectly well 10, at work but some gastric discomfort at times 4 .

Commentary.

The difference in these end-results is very striking, and shows clearly the advantage of performing gastro-jejunostomy at the time of perforation whenever the patient is in a condition to stand it. Moreover, there is no doubt that with gastro-jejunostomy the patients do better and * Abbreviated from. a paper read before the Birmingham Branch of the have a shorter convalescence than without it. A perforated ulcer is an active ulcer, and it is only natural that to put it at rest should increase the patient's chance of recovery. On the other hand, to do more than is absolutely necessary to a patient suffering from a grave abdominal emergency is to invite certain criticism that the immediate mortality will be increased. If my mortality for the whole series, however treated, is greater than the average mortality for perforating ulcer, my method stands condemned, and this is why I have been careful to state my gross mortality of 27.5 per cent., which is, I believe, less than the average.

Obviously, considerable judgement is required to decide when to perform gastro-jejunostomy in these cases, but I find from my notes that I have gradually come to do so more and more frequently. Of the last 15 cases operated on I have performed gastro-jejunostomy in 13; all of them recovered, while the two in which $I$ did not do so died.

\section{CONJUNCTIVITIS IN THE TROPICS.*}

\author{
ROBERT H. ELLIOT, M.D., F.R.C.S., \\ LieutenanT-ColoneL I.M.S.(RET.).
}

I was once told by a surgeon with many years of tropical ophthalmic practice behind him that he did not recognize such a thing as tropical ophthalmology. Such a position premises to $\mathrm{my}$ mind a great lack of perception and of imagination. Tropical practice differs so materially from that in temperate climates as to demand a very special study in order to fit a man for success. We are all of us, as we grow older, conscious of regrets for lost opportunities, but there is no department of ophthalmology which brings up to my mind more often or more acutely the sense of what I might have done and did not do than the study of inflammations of the conjunctiva. I feel that the young man who starts his ophthalmic work in the tropics, awakened to an appreciation of the avenues of research opened up by this line of study, has great possibilities in store for him. With the view of stimulating the interest of some of the younger men in this very interesting subject $I$ propose to review it in a more or less summary manner, and to indicate some of the lines along which I think that research can profitably be conducted.

There is another side to the question. The expansion of our colonies and the movement of great bodies of men to and from the tropics during the war has brought tropical disease to our very doors, and has stimulated an interest in the subject amongst our own medical men practising in Great Britain and in its temperately situated colonies: It is my hope that this bare outline of a great subject may therefore be of some interest to them too.

The habits of the residents in tropical lands, and the climatic conditions which prevail there, are favourable to the implantation of germs within the conjunctival sac and to their growth on its lining membrane. Sun, dust, and wind constitute a triad of evil influence adverse to the maintenance of conjunctival health. All who have lived in Eastern countries are conscious of the drying up of the skin and the rapid exfoliation of its surface layers which are experienced in the hot weather, and which are greatly aggravated when the hot air is in motion, and especially so when it is laden with dust, as it so often is in tropical lands. It used to be suggested that the epidemics of conjunctivitis with which every tropical worker is so familiar are due to the infection of the conjunctivae of the population by germ-laden air. As a matter of fact, the majority of the organisms responsible for the Eastern epidemics of ophthalmia are non-sporing, and we know by expcriment that such are easily killed by drying. I will revert to this subject later on, being content here to lay stress on the view that the action of dust, like that of heat and wind, is probably traumatic, abrading the surface epithelium, causing local congestion, and so preparing the membrane for the growth of pathogenic organisms.

* A lecture delivered at the London School of Tropical Medicine on 